\title{
Side-stepping genetics
}

Lateral DNA Transfer: Mechanisms and Consequences

by Frederic Bushman

Cold Spring Harbor Laboratory. 2001

Hardback, £43/\$59

Howard Ochman

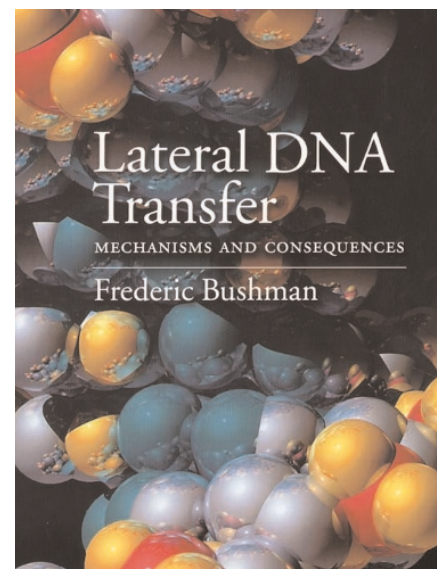

$\mathrm{T}$

he newest title on my shelf was also the hardest to classify. I first put Frederic Bushman's Lateral DNA Transfer in the microbiology section of my library, along with books on mobile DNA. But seeing it up there among the '-ologies' was not quite right; nor did seem to fit in anywhere in either the genetics to human evolution, or the organism to molecular evolution continuum spanning the other shelves. Beginning a new section, much like the one for my burgeoning bioinformatics collection (now cozily next to molecular evolution), might be warranted because, true to its topic, this book is no simple descendent of anything that is currently available. Frederic Bushman has produced a text that will motivate the introduction of a new course into the college curriculum.

Because lateral gene transfer defies what we usually think of as typical Mendelian and Darwinian processes, it has often been regarded as more of a genetic anomaly rather than a unifying feature of life forms. To most, the mention of lateral transfer invokes the same well-worn examples of McClintock's original dissociator and activator elements in maize, and of acquired antibiotic resistance in bacteria. But in its broadest sense, lateral transfer encompasses all genetic sequences not inherited in a strictly vertical manner, and it is indeed pervasive. Such processes can affect virtually any biological entity, either as a vessel, vehicle or beneficiary of lateral gene transfer, and are important in the genetic and phenotypic variation among organisms.

The farrago of events that fall under the heading of lateral DNA transfer invites problems when compiling a text on this topic. Possibly the easiest way of tackling such diversity is to apply systematics, that is, by surveying the array and significance of mobile elements within well-defined taxonomic groups. Of course, the very nature of mobile sequences allows them to transcend traditional taxonomic groupings, and this shifts focus to the range, distribution and classification of the elements themselves. The next factor to consider is mobility within genomes versus that between organisms, both involving similar sorts of elements but usually mediated by very different processes. Finally, there are the complex mechanisms and consequences of DNA transfer, which extend from passive and coincidental to actively parasitic and detrimental. Such topics, despite (or, perhaps, on account of) their diversity and curiosity, have usually been relegated to specialized graduate seminars.

Frederic Bushman's new book departs from previous texts on this topic in several ways. Rather than attempting to be an exhaustive resource for researchers in the field, his book aptly samples from the vast literature and takes special efforts to make it palatable and relevant to a wide audience. Basically, anyone with a rudimentary grasp of contemporary biology can begin to use this text; there is even a brief chapter supplying the essentials of molecular biology for those who managed to sleep through this portion of their introductory biology course at any time over the past few decades.

The book is arranged around some of the most fascinating aspects of horizontal gene transfer, adroitly selected to emphasize its significance and ubiquity, and is roughly organized into processes affecting prokaryotes, those affecting eukaryotes, and finally those linking the domains of life. Students bound for medical school get chapters on bacterial pathogenesis, the immune system and HIV, whereas contemporary interests in genomics will be satisfied with up-to-date information coming from the genome projects of microbes and multicellular creatures. Moreover, the references to primary literature - highlighted at the start of each subheading but annoyingly not cited individually within the text - are extremely thorough, especially as the book is aimed at a general audience of biologists.

Given the novelty of its scope, its approach and its format, are there any shortcomings with Bushman's Lateral DNA Transfer? Surprisingly few; but its highly synthetic content makes it difficult to guess whether, or to what depth, a particular topic is included, or covered, and will impede its use as a general reference. Furthermore, inclusion of some brief sections explaining some of the methods used to uncover and substantiate events of lateral DNA transfer would be useful to readers and researchers alike. Neither of these deficiencies diminishes my enthusiasm for the book, nor my hope that it represents a coming trend. In a day when most college textbooks strive to occupy some established niche - do I count nine biochemistry texts on my shelf? - it is a real pleasure to find a book that has accomplished something new.

Howard Ochman is in the Department of Biochemistry \& Molecular Biophysics, University of Arizona, Tucson, Arizona, USA. e-mail:hochman@email.arizona.edu

\section{New in hardback}

The Bacterial Cell Well

by G. Seltman and O. Holst

Springer-Verlag,

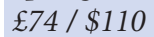

The Evolution of Developmental

Pathways

by A. S. Wilkins

Sinauer,

$£ 42.99 / \$ 54.95$

DNA Microarrays: Gene Expression

Applications

edited by B. R. Jordan

Springer-Verlag,

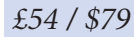

Foundation of Systems Biology

edited by H. Kitano

The MIT Press,

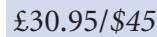

